\title{
Modeling the hydrophysical soil properties and comparative analysis for three systems of functions
}

\author{
Vitaly Terleev ${ }^{1}$, Roman Ginevsky ${ }^{1}$, Viktor Lazarev ${ }^{1}$, Aleksandr Nikonorov ${ }^{1, *}$, \\ Alexander Topaj ${ }^{2}$, Ielizaveta Dunaieva ${ }^{3}$, Aleksey Petrushin ${ }^{4}$, Olga Mitrofanova ${ }^{4,5}$, \\ and Elena Zakharova ${ }^{4}$ \\ ${ }^{1}$ Peter the Great St.Petersburg Polytechnic University, Polytechnicheskaya Str. 29, 195251, \\ St.Petersburg, Russia \\ ${ }^{2}$ LLC «Bureau Hyperborea», Podvoisky ul., 40-2, 193312, St.Petersburg, Russia \\ ${ }^{3}$ Research Institute of Agriculture of Crimea, Kievskaya street, 150, 295543, Simferopol, Russia \\ ${ }^{4}$ Agrophysical Research Institute, Grazhdanskii pr., 14, 195220, St.Petersburg, Russia \\ ${ }^{5}$ St.Petersburg State University, University embankment, 7/9, 199034, St.Petersburg, Russia
}

\begin{abstract}
A functional description of the hydrophysical properties of the soil as a capillary-porous medium is presented. The described functions of water retention capacity and hydraulic conductivity of the soil have common parameters, which are interpreted within the framework of physical and statistical concepts. The practical significance of the proposed functions lies in the fact that the volume of labor-intensive field measurements necessary, for example, for modeling the dynamics of soil moisture, is significantly reduced. To identify the parameters of these functions, it is sufficient to use data only on the water retention capacity of the soil. The parameters identified in this way can be used to predict the ratio of the hydraulic conductivity of the soil to the moisture filtration coefficient. The presented system of the hydrophysical functions of the soil is compared with world analogues using literature data on soils of different texture.
\end{abstract}

\section{Introduction}

The hydrophysical properties of the soil include its water retention capacity and hydraulic conductivity. When describing these properties, the following indicators are used: for water retention capacity, the relationship between the volumetric soil water content $\theta\left[\mathrm{cm}^{3} \cdot \mathrm{cm}^{-3}\right]$ and the capillary pressure of soil moisture $\psi\left[\mathrm{cm} \mathrm{H}_{2} \mathrm{O}\right.$ ]; for hydraulic conductivity (or the ability of the soil to conduct water as a porous body), the dependence of the moisture conductivity coefficient $k\left[\mathrm{~cm} \cdot \mathrm{day}^{-1}\right]$ on the capillary pressure of soil moisture $\psi$ or on volumetric soil water content $\theta$. Direct measurements of the dependences $\theta(\psi), k(\psi)$ or $k(\theta)$ are very laborious. For this reason, research in the direction of creating mathematical models of water retention capacity and hydraulic conductivity of the soil, which can reduce

\footnotetext{
*Corresponding author: coolhabit@yandex.ru
} 
the volume of direct measurements of the dependences $\theta(\psi), k(\psi)$ or $k(\theta)$, is very relevant.

The maximum volume of water per unit volume of soil is estimated by the value of porosity and is called the saturation volumetric soil water content $\theta_{s}[\mathrm{~cm} 3 \cdot \mathrm{cm}-3]$. The minimum volume of water per unit volume of soil at which water has the properties of a liquid is estimated by the maximum hygroscopicity of the soil and is called the residual volumetric soil water content $\theta_{r}[\mathrm{~cm} 3 \cdot \mathrm{cm}-3]$. To assess the saturation of soil with water having the properties of a liquid, an indicator is used, which is called effective soil moisture saturation $S_{e}=\left(\theta-\theta_{r}\right) /\left(\theta_{s}-\theta_{r}\right)$. The space of soil pores occupied by the liquid phase is topologically closed. Therefore, on the one hand, the proportion of the pore space of the soil occupied by the liquid phase is identically equal to the effective soil moisture saturation $S_{e}$. On the other hand, this fraction can be used as the accumulated probability that a randomly selected observation point in the pore space belongs to a liquid rather than a gaseous phase. At the same time, any arbitrary point at the interface between the space formed by the pores sequentially (starting from the smallest) filled with the liquid phase and the space formed by larger pores not filled with the liquid phase is characterized by the same average curvature, which, by law Young-Laplace uniquely corresponds to a certain value of capillary pressure $\psi$. Therefore, between the capillary pressure $\psi$, effective moisture saturation $S_{e}$, or the cumulative probability of the state of soil moisture, which is characterized by capillary pressure $\psi$, there is an unambiguous relationship. As a consequence of Lyapunov's central limit theorem, it seems logical to use the normal law to describe the probability distribution over the values of a random variable determined by capillary pressure in the form of the dependence $S_{e}(\psi)$.

The capillary pressure of soil moisture, at which the «air entry» into the soil and water displacement begins, will be called the «air entrance pressure» and denoted by $\psi_{e}$. (Index «e» means «entrance»). This means, firstly: $S_{e}=1$ at $\psi \geq \psi_{e}$; secondly, $S_{e}<1$ at $\psi<\psi_{e}$. Therefore, to formulate the dependence $S_{e}(\psi)$ at $\psi<\psi_{e}$ it seems appropriate to use a random variable that contains the difference $\left(\psi-\psi_{e}\right)$. However, this difference at $\psi<\psi_{e}$ does not change sign; therefore, it cannot be accepted as a normally distributed random variable. Therefore, the authors propose using the random variable $\ln \left(\left(\psi-\psi_{e}\right) /\left(\psi_{0}-\psi_{e}\right)\right)$ with zero general mean and dispersion $\sigma^{2}$. Parameter $\psi_{0}$ represents the value of capillary pressure at which the probability distribution density over the values of the proposed random variable reaches a maximum.

The purpose of the study is the justification and presentation of the hydrophysical properties of the soil in the form of mathematical models.

\section{Materials and methods}

In [1], the following description is proposed for the function of soil water retention capacity:

$$
S_{e}=\left[\begin{array}{l}
\frac{1}{2} \operatorname{erfc}\left(\frac{n \sqrt{\pi}}{4} \ln \left(-\alpha\left(\psi-\psi_{e}\right)\right)\right), \quad \psi<\psi_{e} \\
1, \quad \psi \geq \psi_{e}
\end{array}\right.
$$

where: $\operatorname{erfc}(x)=1-\frac{2}{\sqrt{\pi}} \int_{0}^{x} \exp \left(-t^{2}\right) d t-$ additional error function; $n=4 /(\sigma \sqrt{2 \pi})$, $\alpha=-1 /\left(\psi_{0}-\psi_{e}\right) \quad[\mathrm{cm} \mathrm{H} 2 \mathrm{O}-1], \quad \psi_{e}[\mathrm{~cm} \mathrm{H} 2 \mathrm{O}], \psi_{0} \quad[\mathrm{~cm} \mathrm{H} 2 \mathrm{O}]<\psi_{e}-$ interpreted parameters (taking into account hysteresis: for drying branches $\psi_{e} \leq 0$; for wetting branches $\psi_{e} \geq 0$ ). 
In the particular case at $\psi_{e}=0$, function (1) reduces to the model of water retention capacity of the soil proposed by Kosugi [2]. At the same time, a continuous approximation of relation (1) in the class of elementary functions using the simplified Winitzki formula [3] was proposed in [1]:

$$
S_{e}=\left[\begin{array}{l}
\left(1+\left(-\alpha\left(\psi-\psi_{e}\right)\right)^{n}\right)^{-1}, \psi<\psi_{e} \\
1, \psi \geq \psi_{e}
\end{array}\right.
$$

In the particular case at $\psi_{e}=0$, function (2) reduces to the soil water retention capacity model proposed by Haverkamp et al. [4]. Among the world's most well-known analogues of functions (1) and (2) is an empirical model of soil water retention capacity proposed by Van Genuchten [5]:

$$
S_{e}=\left[\begin{array}{l}
\left(1+(-\alpha \psi)^{n}\right)^{-m}, \psi<0 \\
1, \psi \geq 0
\end{array}\right.
$$

where $\alpha$ [cm H2O-1], $n$ and $m$ - empirical parameters of position and shape ( $m=1-$ $1 / n, n>1)$.

Mualem in [6] proposed a formula for calculating the ratio of soil hydraulic conductivity to moisture filtration coefficient $k_{s}$ [cm-day-1] (relative hydraulic conductivity $k / k_{s}$ ). In [1], using this formula a function of the relative hydraulic conductivity of the soil was obtained:

$$
\frac{k}{k_{s}}=\left[\begin{array}{l}
\frac{\sqrt{S_{e}}}{4}\left(\operatorname{erfc}\left(\operatorname{inverfc}\left(2 S_{e}\right)+\frac{2}{n \sqrt{\pi}}\right)\right)^{2}, \theta<\theta_{s} \\
1, \theta=\theta_{s}
\end{array}\right.
$$

where inverfc $(\operatorname{erfc}(x))=x$.

In the particular case when $\psi_{e}=0$, function (4) reduces to the model proposed by Kosugi [7]. In [1], a continuous approximation of relation (4) in the class of elementary functions using the simplified Winitzki formula [3] is proposed:

$$
\frac{k}{k_{s}}=\left[\begin{array}{l}
\sqrt{S_{e}}\left(1-\left(1-S_{e}^{-1}\right) \exp \left(\frac{8}{n \pi}\right)\right)^{-2}, \theta<\theta_{s} \\
1, \theta=\theta_{s} .
\end{array}\right.
$$

It should be noted that functions (1), (2), (4) and (5) have a common set of physicallystatistically interpreted parameters.

The method for calculating the relative hydraulic conductivity of the soil according to the Mualem formula using the soil water holding capacity model (3) is widely known in the world as the Mualem-Van Genuchten method. The function of the relative hydraulic conductivity of the soil, calculated by this method, has the form:

$$
\frac{k}{k_{s}}=\left[\begin{array}{l}
\sqrt{S_{e}}\left(1-\left(1-S_{e}{ }^{1 /(1-1 / n)}\right)^{(1-1 / n)}\right)^{2}, \theta<\theta_{s} \\
1, \theta=\theta_{s}
\end{array}\right.
$$

Functions (3) and (6) have a common set of empirical parameters of the position and shape of the curves that graphically depict these functions, i.e. these parameters have no physical meaning. 
We introduce a number of notations. The soil water retention capacity functions (1) - (3) are denoted, respectively: WRC-KT, WRC-HT, WRC-VG (WRC - water retention capacity). The functions of the relative hydraulic conductivity of the soil (4) - (6) are denoted, respectively: RHC-MKT, RHC-MT, RHC-MVG (RHC - relative hydraulic conductivity). Since the listed functions are usually used in pairs, we group their functions as follows: system \# 1 (WRC-VG and RHC-MVG); system \# 2 (WRC-KT and RHCMKT), system \# 3 (WRC-HT and RHC-MT). The most famous and widely used is the system \# 1. However, system \# 1 has a significant drawback, which consists in the absence of physical meaning of the parameters, and also the limitation of $n>1$. These shortcomings are the result of computational difficulties that Van Genuchten encountered when calculating the relative hydraulic conductivity function of the soil by the Mualem formula using the WRC-HT function (at $\psi_{e}=0$ ). That is why Van Genuchten proposes the WRC-VG function, which is the result of transforming the WRC-HT function (for $\psi_{e}=0$ ) by raising the denominator to the power: for this, an additional parameter $m=1-1 / n, m>0$. is arbitrarily introduced. This transformation allows integration using the Mualem formula. However, this result is achieved at the cost of refusing to interpret the parameters, as well as at the cost of limiting $n>1$. Note that for large values of the parameter $n$, the MualemVan Genuchten method allows one to obtain a low error in estimating the relative hydraulic conductivity of the soil using the RHC-MVG function with parameters that are identified by point approximation of experimental data on the water retention capacity of the soil using the WRC-VG function. But the problem arises for small values of the parameter $n$, when the Mualem - Van Genuchten method has a higher error, as evidenced by the dubious result for the Beit Netofa clay [1]. Using the functions of systems \# 2 and \# 3 in hydrophysical calculations avoids this problem. In passing, we note that system \# 3 (for $\psi_{e}=0$ ) is a mathematically correct solution to the Van Genuchten problem in its original formulation. The parameters of system \# 3 have a physical and statistical sense. The following are the results of a comparative analysis of three systems of hydrophysical functions using four soils of different textures as an example [8].

\section{Results and discussion}

Table 1 shows the parameter values for the three compared systems of hydrophysical functions. Table 2 shows the errors of the point approximation of the experimental data on water retention capacity, presented in the form of the dependence $\theta(\psi)$, as well as the prediction of the relative hydraulic conductivity $k(\theta) / k_{s}$ of soil unsaturated with moisture for each of the three compared systems of hydrophysical functions. Bold text indicates minimum errors. Table 2 shows that the errors for the point approximation of experimental data on the water retention capacity of soils are comparable for all three systems of functions. To predict relative hydraulic conductivity, the results differ more significantly. For the soils «3001 Weld silty clay loam» and «4122 Sinai sand», the errors of all three systems are comparable, which can be explained by the relatively high values of parameter $n$, which should be greater than unity in system \# 1 . However, for soil «3102 Yolo light clay» the errors of system \# 1 are noticeably higher than the errors of systems \# 2 and \# 3 . This indicates that the functions of systems \# 2 and \# 3 are physically more adequate, and indicates their greater preference for hydrophysical calculations.

Table 3 shows the values of the correlation coefficients between the simulation results and experimental data. The highest values are in bold. In Fig. 1-2 on the left side presents experimental data on the water retention capacity of soils (round dots); the right side of the figures shows experimental data on the relative hydraulic conductivity of soils (square dots). The solid curves in these figures show the results of identification by pointwise approximation of data on water retention capacity and the results of predicting the relative 
hydraulic conductivity of four studied soils of different textures. Moreover, different colors were used for various systems of functions: \# 1 - red, \# 2 - blue, \# 3 - green.

Table 1. Identification results of soil-hydrophysical parameters of three systems of functions by approximating experimental data on the water retention capacity of four soils

\begin{tabular}{|c|c|c|c|c|c|c|}
\hline \multirow{2}{*}{$\begin{array}{l}\text { Catalog } \\
\text { number [8] } \\
\text { and soil name }\end{array}$} & \multirow[b]{2}{*}{ System number } & \multicolumn{5}{|c|}{ Function parameters } \\
\hline & & $\begin{array}{c}\theta_{s} \\
\mathbf{c m}^{3} \cdot \mathbf{c m}^{-3}\end{array}$ & $\begin{array}{c}\theta_{r} \\
\mathbf{c m}^{3} \cdot \mathbf{c m}^{-3}\end{array}$ & $\begin{array}{c}\psi_{e} \\
\operatorname{cm~} \mathbf{H}_{2} \mathrm{O}\end{array}$ & $\begin{array}{c}\alpha, \\
\operatorname{cm} \mathbf{H}_{2} \mathrm{O}^{-1}\end{array}$ & $\boldsymbol{n}$ \\
\hline \multirow{3}{*}{$\begin{array}{l}3001 \text { Weld } \\
\text { silty clay loam }\end{array}$} & 1 & 0.470 & 0.162 & - & 0.0131 & 5.978 \\
\hline & 2 & 0.470 & 0.167 & 0 & 0.0125 & 5.496 \\
\hline & 3 & 0.470 & 0.165 & 0 & 0.0125 & 5.688 \\
\hline \multirow{3}{*}{$\begin{array}{l}3102 \text { Yolo } \\
\text { light clay }\end{array}$} & 1 & 0.495 & 0.209 & - & 0.0252 & 1.756 \\
\hline & 2 & 0.495 & 0.238 & 0 & 0.0137 & 1.376 \\
\hline & 3 & 0.495 & 0.236 & 0 & 0.0136 & 1.419 \\
\hline \multirow{3}{*}{$\begin{array}{l}4122 \text { Sinai } \\
\text { sand }\end{array}$} & 1 & 0.270 & 0.014 & - & 0.0227 & 4.687 \\
\hline & 2 & 0.270 & 0.014 & 0 & 0.0209 & 4.167 \\
\hline & 3 & 0.270 & 0.014 & 0 & 0.0210 & 4.367 \\
\hline \multirow{3}{*}{$\begin{array}{l}3002 \text { Amarillo } \\
\text { silty clay loam }\end{array}$} & 1 & 0.455 & 0.129 & - & 0.0100 & 5.055 \\
\hline & 2 & 0.455 & 0.138 & 0 & 0.0096 & 4.676 \\
\hline & 3 & 0.455 & 0.133 & 0 & 0.0094 & 4.795 \\
\hline
\end{tabular}

Table 2. Comparison of the errors of the point approximation of the measured water retention capacity and prediction of the relative hydraulic conductivity of four soils

\begin{tabular}{|l|c|c|c|c|c|c|}
\hline \multirow{2}{*}{$\begin{array}{l}\text { Catalog } \\
\text { number } \\
{\left[\begin{array}{l}\mathbf{8}] \text { and } \\
\text { soil name }\end{array}\right.}\end{array}$} & \multicolumn{2}{|c|}{ System \#1 } & \multicolumn{2}{c|}{ System \#2 } & \multicolumn{2}{c|}{ System \#3 } \\
\cline { 2 - 7 } & WRC-VG & RHC-MVG & WRC-KT & RHC-MKT & WRC-HT & RHC-MT \\
\hline $\begin{array}{l}\text { 3001 Weld } \\
\text { silty clay } \\
\text { loam }\end{array}$ & $\mathbf{0 . 0 1 3 2}$ & 0.0364 & 0.0137 & 0.0363 & 0.0139 & $\mathbf{0 . 0 3 5 6}$ \\
\hline $\begin{array}{l}\text { 3102 Yolo } \\
\text { light clay }\end{array}$ & $\mathbf{0 . 0 0 4 4}$ & 0.1167 & 0.0057 & 0.0941 & 0.0063 & $\mathbf{0 . 0 6 7 4}$ \\
\hline $\begin{array}{l}\text { 4122 Sinai } \\
\text { sand }\end{array}$ & $\mathbf{0 . 0 1 8 8}$ & 0.0273 & 0.0202 & 0.0244 & 0.0196 & $\mathbf{0 . 0 2 3 4}$ \\
\hline $\begin{array}{l}\text { 3002 } \\
\text { Amarillo } \\
\text { silty clay } \\
\text { loam }\end{array}$ & 0.0065 & 0.0280 & 0.0078 & 0.0216 & $\mathbf{0 . 0 0 6 2}$ & $\mathbf{0 . 0 1 3 7}$ \\
\hline
\end{tabular}

The results of assessing the reliability of differences in the prediction error of the relative hydraulic conductivity of the studied soils (soils) according to the Williams-Kloot criterion [9] (with confidence probabilities of 0.95 and 0.975) are given in Table 4. 
Table 3. Correlation of the results of the point approximation of the measured water retention capacity and the results of predicting the relative hydraulic conductivity with the measured data on four soils

\begin{tabular}{|l|c|c|c|c|c|c|}
\hline \multirow{2}{*}{$\begin{array}{l}\text { Catalog } \\
\text { number [8] } \\
\text { and soil name }\end{array}$} & \multicolumn{2}{|c|}{ System \#1 } & \multicolumn{2}{c|}{ System \#2 } & \multicolumn{2}{c|}{ System \#3 } \\
\cline { 2 - 7 } & WRC-VG & RHC-MVG & WRC-KT & RHC-MKT & WRC-HT & RHC-MT \\
\cline { 2 - 7 } & $\mathbf{0 . 9 9 1 3}$ & $\mathbf{0 . 9 9 2 6}$ & 0.9904 & 0.9924 & 0.9903 & 0.9925 \\
\hline $\begin{array}{l}3001 \text { Weld silty } \\
\text { lay loam }\end{array}$ & $\mathbf{0 . 9 9 8 6}$ & 0.9508 & 0.9976 & 0.9709 & 0.9971 & $\mathbf{0 . 9 8 5 4}$ \\
\hline $\begin{array}{l}3102 \text { Yolo light } \\
\text { clay }\end{array}$ & 0.9770 & 0.9975 & 0.9741 & 0.9978 & $\mathbf{0 . 9 7 5 6}$ & $\mathbf{0 . 9 9 8 0}$ \\
\hline 4122 Sinai sand & 0.9987 & 0.9985 & 0.9981 & 0.9990 & $\mathbf{0 . 9 9 8 8}$ & $\mathbf{0 . 9 9 9 6}$ \\
\hline $\begin{array}{l}\text { 3002 Amarillo } \\
\text { silty clay loam }\end{array}$ & & &
\end{tabular}
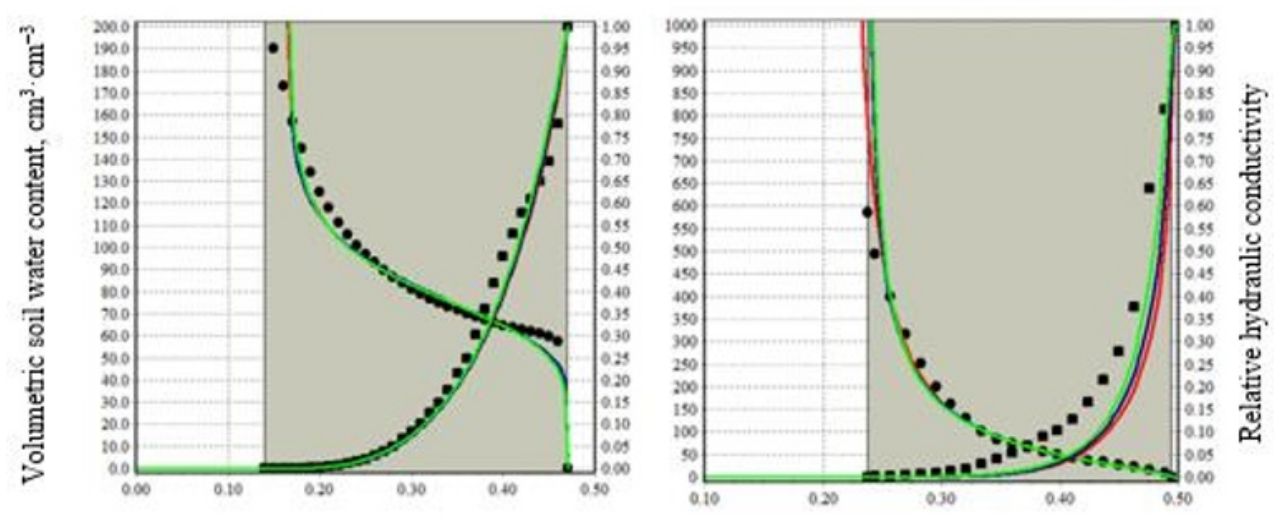

Fig. 1. Capillary pressure of moisture (abs. value), $\mathrm{cm} \mathrm{H}_{2} \mathrm{O}$ : «3001 Weld silty clay loam» (left), «3102 Yolo light clay» (right).
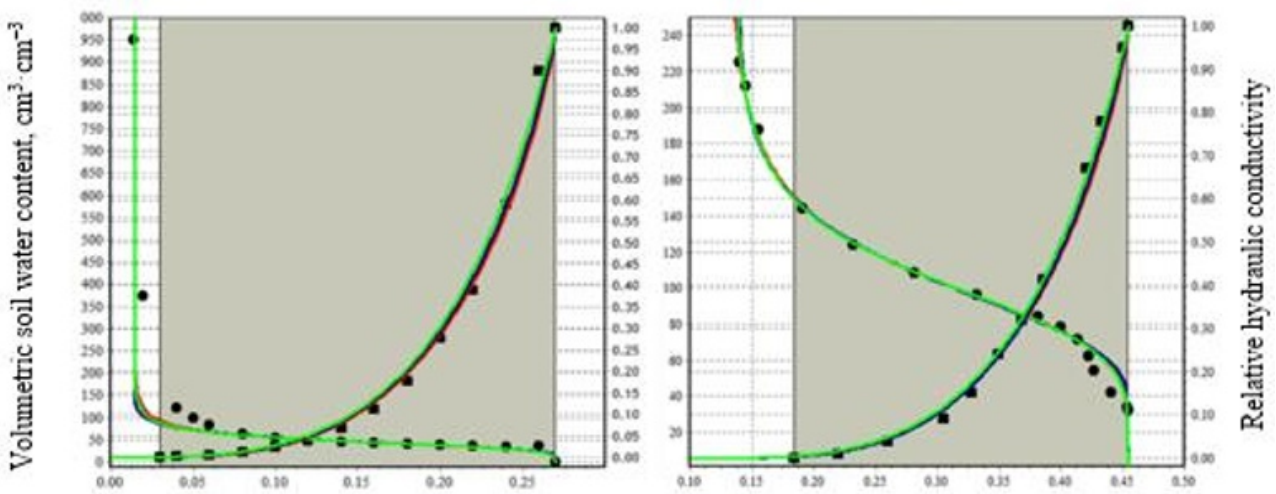

Fig. 2. Capillary pressure of moisture (abs. value), $\mathrm{cm} \mathrm{H}_{2} \mathrm{O}$ : «4122 Sinai sand» (left), «3002 Amarillo silty clay loam» (right). 
Table 4. Assessment of the reliability of differences in the prediction error of the relative hydraulic conductivity of four soils for three pairwise compared systems using the Williams-Kloot criterion.

\begin{tabular}{|c|c|c|c|c|c|c|c|c|c|}
\hline \multirow{3}{*}{$\begin{array}{l}\text { Catalog } \\
\text { number } \\
{[8] \text { and }} \\
\text { soil } \\
\text { name }\end{array}$} & \multicolumn{9}{|c|}{$y-\frac{y_{1}+y_{2}}{2}=\lambda\left(y_{1}-y_{2}\right)$, where $y-$ measured data } \\
\hline & \multicolumn{3}{|c|}{$\begin{array}{l}y_{1}: \text { RHC-MVG, } \\
y_{2}: \text { RHC-MKT }\end{array}$} & \multicolumn{3}{|c|}{$\begin{array}{c}y_{1}: \text { RHC-MVG, } \\
y_{2}: \text { RHC-MT }\end{array}$} & \multicolumn{3}{|c|}{$\begin{array}{c}y_{1}: \text { RHC-MKT, } \\
y_{2}: \text { RHC-MT }\end{array}$} \\
\hline & $\lambda$ & $\lambda_{0.95}$ & $\lambda_{0.975}$ & $\lambda$ & $\lambda_{0.95}$ & $\lambda_{0.975}$ & $\lambda$ & $\lambda_{0.95}$ & $\lambda_{0.975}$ \\
\hline \multirow{2}{*}{$\begin{array}{l}3001 \\
\text { Weld silty } \\
\text { clay loam }\end{array}$} & 1.309 & 2.968 & 3.569 & 0.490 & 1.050 & 1.263 & 0.761 & 1.633 & 1.964 \\
\hline & \multicolumn{3}{|c|}{$y_{1}$ and $y_{2}$ are equivalent } & \multicolumn{3}{|c|}{$y_{1}$ and $y_{2}$ are equivalent } & \multicolumn{3}{|c|}{$y_{1}$ and $y_{2}$ are equivalent } \\
\hline \multirow{2}{*}{$\begin{array}{l}3102 \\
\text { Yolo light } \\
\text { clay }\end{array}$} & -2.865 & 0.899 & 1.087 & $0 . \overline{-}$ & 0.374 & 0.453 & -1.359 & 0.654 & 0.791 \\
\hline & \multicolumn{3}{|c|}{$\begin{array}{l}y_{2} \text { more precisely than } \\
y_{1}\end{array}$} & \multicolumn{3}{|c|}{$\begin{array}{l}y_{2} \text { more precisely than } \\
y_{1}\end{array}$} & \multicolumn{3}{|c|}{$y_{2}$ more precisely than $y_{1}$} \\
\hline \multirow{2}{*}{$\begin{array}{l}4122 \\
\text { Sinai } \\
\text { sand } \\
\end{array}$} & -2.232 & 2.244 & 2.743 & $\begin{array}{c}- \\
0.621\end{array}$ & 0.817 & 0.999 & -0.773 & 1.315 & 1.608 \\
\hline & \multicolumn{3}{|c|}{$y_{1}$ and $y_{2}$ are equivalent } & \multicolumn{3}{|c|}{$y_{1}$ and $y_{2}$ are equivalent } & \multicolumn{3}{|c|}{$y_{1}$ and $y_{2}$ are equivalent } \\
\hline \multirow{2}{*}{$\begin{array}{l}3002 \\
\text { Amarillo } \\
\text { silty clay } \\
\text { loam }\end{array}$} & -3.725 & 0.633 & 0.779 & $-\overline{1}$ & 0.639 & 0.786 & -1.465 & 1.149 & 1.412 \\
\hline & \multicolumn{3}{|c|}{$\begin{array}{l}y_{2} \text { more precisely than } \\
y_{1}\end{array}$} & \multicolumn{3}{|c|}{$\begin{array}{l}y_{2} \text { more precisely than } \\
y_{1}\end{array}$} & \multicolumn{3}{|c|}{$y_{2}$ more precisely than $y_{1}$} \\
\hline
\end{tabular}

The results obtained indicate a more accurate description of the hydrophysical properties of the soil using the functions of systems \# 2 and \# 3. It can be assumed that system \# 1 in two of four comparisons is reliably inferior to systems \# 2 and \# 3. It can be assumed that the reason for this is that the parameters of system \# 1 do not have physical sense, and that the exponential parameter of system \# 1 is constrained by $n>1$. Probably, these shortcomings are the reason for the low error in predicting the relative hydraulic conductivity using parameters identified by the Beit Netofa clay data. It was previously shown that the problem with Beit Netofa clay was successfully solved by using the functions of systems \# 2 and \# 3. The results obtained in this article further confirm the advantages of systems \# 2 and \# 3 over system \# 1 and can be successfully used in solving practical problems in the field of hydraulic engineering and land management [10-18].

\section{Conclusions}

System \# 1 in half of the cases considered reliably has the greatest error compared to systems \# 2 and \# 3. Moreover, system \# 3 in half of the cases considered reliably has the smallest error compared to systems \# 1 and \# 2. To model the hydrophysical properties of soils from a wide range of texture varieties, the result allows us to recommend system \# 3 as a set of physically justified, sufficiently accurate, correctly formulated, and convenient for calculating mathematical relations from the class of elementary functions.

The reported study was funded by RFBR according to the research projects No. 19-04-00939-a, No. 19-016-00148-a.

\section{References}

1. V.V. Terleev, W. Mirschel, V.L. Badenko, I.Yu. Guseva, Eurasian Soil Science, 50(4), 445-455 (2017) 
2. K. Kosugi, Water Resour. Res., 30, 891-901 (1994)

3. S. Winitzki, A handy approximation for the error function and its inverse (in https://sites.google.com/site/winitzki/sergei-winitzkis-files/erfapprox.pdf?attredirects=0).

4. R. Haverkamp, M. Vauclin, J. Touma, P.J. Wierenga, G. Vachaud, Soil Sci. Soc. Am. J., 41, 285-294 (1977)

5. M.Th. Van Genuchten, Soil Sci. Soc. Am. J., 44, 892-989 (1980)

6. Y. Mualem, Water Resour. Res., 12, 513-522 (1976)

7. K. Kosugi, Water Resour. Res., 32, 2697-2703 (1996)

8. Y. Mualem, A catalogue of the hydraulic properties of unsaturated soils (Research Project 442. Technion, Israel Institute of Technology, Haifa, Israel, 1976)

9. A.I. Kobzar, Prikladnaya matematicheskaya statistika. Dlya inzhenerov $i$ nauchnyx rabotnikov (Izd. Fizmatlit, Moskva) (rus)

10. V. Terleev, E. Petrovskaia, N. Sokolova, A. Dashkina, I. Guseva, V. Badenko, Y. Volkova, O. Skvortsova, O. Nikonova, S. Pavlov, A. Nikonorov, V. Garmanov, W. Mirschel, MATEC Web of Conferences 5(3), 01013 (2016)

11. O. Degtyareva, G. Degtyarev, I. Togo, V. Terleev, A. Nikonorov, Y. Volkova, Procedia Engineering, 165, 1619-1628 (2016)

12. A. Nikonorov, V. Terleev, S. Pavlov, I. Togo, Y. Volkova, T. Makarova, V. Garmanov, D. Shishov, W. Mirschel, Procedia Engineering, 165, 1741-1747 (2016)

13. V. Terleev, E. Petrovskaia, A. Nikonorov, V. Badenko, Y. Volkova, S. Pavlov, N. Semenova, K. Moiseev, A. Topaj, W. Mirschel, MATEC Web of Conferences, 73, 03001 (2016)

14. M.G. Ryzhakova, V.I. Maslikov, A.N. Chusov, V.V. Korablev, Applied Mechanics and Materials, 675-677, 761-769 (2014)

15. Kh.V. Il'ina, N.M. Gavrilova, E.A. Bondarenko, M.Ju. Andrianova, A.N. Chusov, Magazine of Civil Engineering, 76, 241-254 (2017)

16. A. Chusov, V. Maslikov, D. Molodtsov, O. Manukhina, Advances in Intelligent Systems and Computing, 692, 1046-1054 (2018)

17. M.P Fedorov, V.I. Maslikov, V.L. Badenko, A.N. Chusov, D.V. Molodtsov, Power Technology and Engineering, 51(4), 365-370 (2017)

18. V. Umanets, L. Kalitova, D. Kalitov, A. Chusov, E. Umanets, International Multidisciplinary Scientific GeoConference Surveying Geology and Mining Ecology Management, SGEM, 1(5), 135-144 (2015) 